\title{
Overexpression of MACC1 and Its significance in human Breast Cancer Progression
}

Yongbo Huang ${ }^{1,2 \dagger}$, Huizhong Zhang ${ }^{3 \dagger}$, Junchao Cai ${ }^{1,2}$, Lishan Fang ${ }^{1,2}$, Jueheng $\mathrm{Wu}^{1,2}$, Caisheng Y $\mathrm{e}^{4}$, Xun Zhu $u^{1,2}$ and Mengfeng $\mathrm{Li}^{1,2^{*}}$

\begin{abstract}
Background: Metastasis-associated in colon cancer-1 (MACC1) was first identified as a transcriptional activator for proto-oncogene c-MET expression, and its overexpression is frequently associated with metastatic progression for multiply tumor types. In the present study, we analyzed for the first time the expression of MACC1 in breast cancer and its correlation with clinicopathologic features, including metastasis and patient survival.

Results: MACC1 protein expression was analyzed in two cohorts of clinicopathologically characterized breast cancer using immunohistochemistry. Statistical analysis showed a significant correlation of MACC1 expression with the primary tumor, lymph node metastasis, distant metastasis classifications as well as the clinical staging in breast cancer patients. Moreover, overexpression of MACC1 was associated with both a reduced recurrence-free survival (RFS) and poorer patients' overall survival (OS). Multivariate analysis with a Cox proportional-hazards model suggested that MACC1 expression was an independent prognostic indicator for RFS and OS. Stratification of breast cancer patients according to the estrogen receptor (ER) status revealed that MACC1 was prognostic for both ER-negative and ER-positive patients.
\end{abstract}

Conclusions: MACC1 may represent a potentially useful biomarker for the prognosis of breast cancer patients and might be involved in progression of breast cancer.

Keywords: Biomarker, Breast cancer, Cancer progression, MACC1, Metastasis

\section{Background}

Metastasis-associated in colon cancer-1 (MACC1) was first identified to be overexpressed in primary and metastatic tumor specimens of colon cancer as compared to normal colon mucosa and was found to be indicative of metastasis as well as poor survival of the patients. Furthermore, MACC1 has been found to stimulate proliferation, motility and invasion in colon cancer cells through transcriptionally upregulating c-MET [1]. Moreover, studies by other researchers have also linked MACC1 upregulation to cancer development and progression in several types of solid tumors, including lung adenocarcinoma, gastric cancer and hepatocellular

\footnotetext{
* Correspondence: limf@mail.sysu.edu.cn

${ }^{\dagger}$ Equal contributors

'Department of Microbiology, Zhongshan School of Medicine, Sun Yat-Sen University, Guangzhou, Guangdong 510080, China

${ }^{2}$ Key Laboratory of Tropical Disease Control (Sun Yat-Sen University), Ministry of Education, Guangzhou, Guangdong 510080, China

Full list of author information is available at the end of the article
}

carcinoma (HCC) [2-6]. These studies revealed that MACC1 might play a role in the recurrence, metastasis and patient survival in various types of human cancers.

Worldwide, breast cancer is by far the most common cancer in women, and the second most common type of cancer for the general population [7]. Incidence of the disease continues to rise in many countries [8]. Although patient survival for breast cancer has been improved in recent decades [9], the outcome of patients with metastatic breast cancer remains poor with a median overall survival time of 2 to 3 years [10]. It is estimated that 6-10\% of breast cancer patients have undergone metastasis at diagnosis $[11,12]$. Moreover, breast cancer metastasis can occur years or decades after mastectomy [13]. The poor outcome of metastatic breast cancer patients underscores the importance of defining molecular factors responsible for cancer metastasis. Therefore, identifying risk markers to elucidate pathways responsible for breast cancer metastasis is important for the improvement 
of the risk classification in patients as well as discovery of therapeutic targets.

Breast cancer is a heterogeneous disease with a variety of different molecular subtypes and varied clinical outcomes. To date, molecular classification of breast cancer based on the estrogen receptor (ER), progesterone receptor (PR) and HER2 expression status in clinical setting to differentiate a prognosis and guide treatment. Because of the strong predictive importance of ER to endocrine therapy, breast cancer is generally classified into ER+ and ER- subtypes. Despite existing controversies over the issue, expression of ER is reportedly an important favorable prognostic marker in the first 5 years after diagnosis [14]. On the other side, ER- breast cancers generally have worse outcomes and less treatment options than ER+ disease [15]. However, a subset of ERbreast cancers, such as adenoid cystic carcinoma and secretary carcinoma, are ER-negative and exhibit an optimistic prognosis [16,17]. In this context, biomarkers that can identify individuals with a favorable prognosis among ER- negative breast cancer patients, for whom the toxic chemotherapy might be avoidable, are of value in choosing appropriate adjuvant therapy. Unfortunately, insufficient availability of biomarkers for such a purpose remains a challenge in the clinic.

HER2, a member of the receptor tyrosine kinases (RTK) family that are hyperactive in breast cancer, plays an important role in the initiation and progression of the disease and is associated with poor disease-free and overall survival [18-21]. Clinical trials have shown that treatment with anti-HER2 monoclonal antibodies for breast cancer cases that overexpress HER2 is effective in increasing patient survival $[21,22]$. However, overexpression of HER2 has been found in only approximately $25 \%$ of breast cancer, highlighting the importance of identifying other RTKs involved in the pathogenesis of the disease. One of such potential candidates is c-MET, the product of the protooncogene c-MET, overexpression of which has been widely reported in breast cancer, and deregulation of c-MET and its ligand, hepatocyte growth factor/scatter factor (HGF/SF), has been found to promote breast cancer progression and correlates with poor survival [23-25] (also visit http://www.vai.org/Met/Index.aspx for a comprehensive list of HGF/SF, c-MET and cancer references). Aberrant activation of the HGF/c-MET pathway can be caused by c-MET mutations, receptor overexpression and amplification, as well as by elevated HGF [26]. In addition, upregulation of MACC1, which controls c-MET transcription, might be a new regulatory mechanism that leads to c-MET activation. However, the expression level of MACC1 in breast cancer and its correlation with the clinical outcome of the disease is unknown. To address this issue, we examined for the first time the expression status of MACC1 in human breast cancer in this study. By using two large cohorts of breast cancer cases, we have found that the level of MACC-1 significantly correlates with the clinical staging and tumor-node-metastasis (TNM) classification of the disease. More importantly, our study also strongly suggests that MACC1 might be an independent biomarker for the prediction of progression and prognosis of breast cancer.

\section{Results \\ MACC1 expression level and Clinicopathologic Characteristics}

MACC1 expression level was firstly tested by Western blotting analysis in eight paired normal breast tissue and breast tumor specimens from the same patients. As shown in Figurer 1A, protein levels of MACC1 were differentially upregulated in all 8 breast cancer samples as compared with their matched adjacent non-tumor tissue specimens. In order to determine whether MACC1 is clinically correlated with breast cancer progression, the expression of MACC1 was examined by IHC in two large cohorts of breast cancer patients. The clinicopathologic characteristics of the study population are summarized in Table 1. The IHC analysis showed that MACC1 staining was only marginally detectable in normal breast tissue, but in contrast, it was found dramatically overexpressed in breast cancer lesions (Figure 1B and C). In cohorts 1 and 2, 55.5\% and $60.0 \%$ of patients exhibited high levels of MACC1 expression in their tumor samples, respectively, while, the remaining $44.5 \%$ and $40.0 \%$ of tumor samples exhibited low expression of MACC1. MACC1 expression was not associated with age, ER and PR status and Her2 status, but was significantly associated with $\mathrm{T}$ classification, $\mathrm{N}$ classification, distant metastasis status, and clinical stage in both study cohorts (Table 2). Taken as a whole, the expression of MACC1 was positively correlated with clinical staging and TNM classification of breast cancer.

\section{MACC1 expression level in breast tumor is associated with reduced recurrence-free survival}

The finding that MACC1 overexpression correlated with positive lymph node status and was more commonly present in patients with distant metastasis at diagnosis prompted us to further analyze the association of MACC1 expression with breast cancer recurrence after treatment in cohort 1. Accordingly, patients who developed metastatic disease at diagnosis, as detected and confirmed by computed tomography and/or magnetic resonance imaging and/or positron emission tomography, were excluded from this analysis. Among the 212 cases without any detectable metastases in common metastatic organs at diagnosis, 40 patients (19.0\%) relapsed during a median follow-up period of 51 months, and the recurrence-free survival (RFS) was analyzed. 


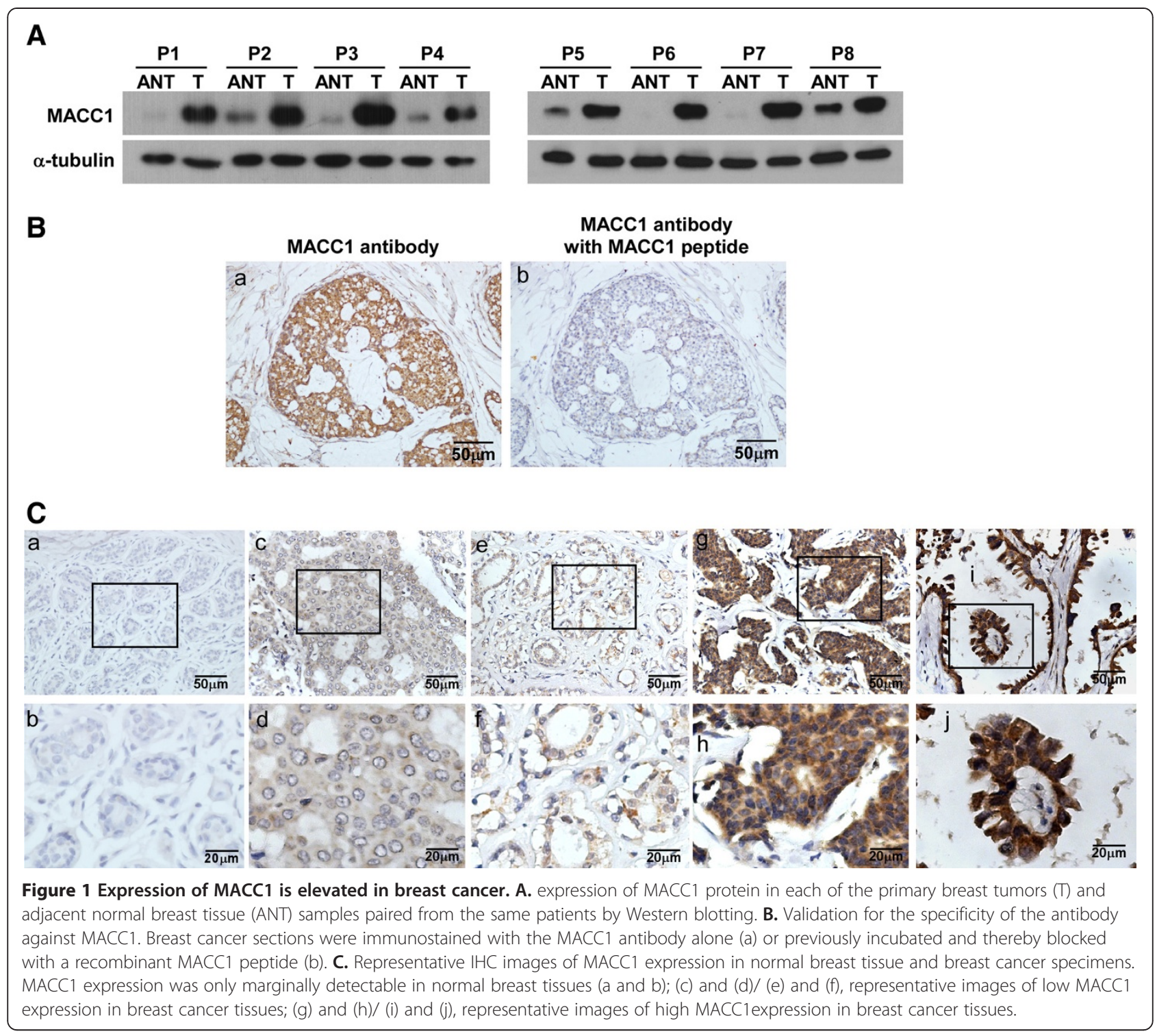

Our data showed that the low-MACC1 expression group exhibited a lower rate of recurrence (10.6\%) during the follow-up compared with the high-MACC1 group (26.9\%, $P=0.002)$. Moreover, Kaplan-Meier analysis and the log-rank test were used to calculate the effect of MACC1 expression on RFS, and the results showed that RFS was significantly different between the low- and high-MACC1 expression groups $(P=0.002$, Figure $2 \mathrm{~A})$, strongly indicating that MACC1 overexpression generally correlated with breast cancer recurrence. As breast cancer patients with positive lymph nodes $(\mathrm{LN}+)$ are far more likely to relapse than those with negative lymph nodes (LN-)[27], in order to investigate the prognostic value of MACC1 in $\mathrm{LN}$ - and $\mathrm{LN}+$ patients, $\mathrm{LN}$ status stratification were employed for further Kaplan-Meier analysis on correlations of RFS with the MACC1 expression level in these two groups. The analysis found that the MACC1 expression is significantly associated with RFS of patients in both LN-negative and positive groups (Figure 2B and C). Furthermore, a multivariate Cox regression analysis showed that after adjustment of tumor size and lymph node status, MACC1 was an independent prognostic factor for RFS in breast cancer $(P=0.006$, Hazard ratio: $2.378,95 \%$ CI, and 1.279 to 4.424 , Table 3 ). Collectively, our results revealed that high MACC1 expression not only was more commonly found in patients with LN or distant organ metastasis, but also represented an independent prognosis marker for RFS.

\section{MACC1 expression and overall survival analysis in test and verification cohorts}

We next examined the effectiveness of MACC1 expression in predicting overall survival of breast cancer patients. Kaplan-Meier analysis and log-rank test were 
Table 1 Clinicopathologic characteristics of patient samples in Cohorts 1 and 2

\begin{tabular}{|c|c|c|c|c|}
\hline \multirow[t]{2}{*}{ Characteristic } & \multicolumn{2}{|c|}{ Cohort 1} & \multicolumn{2}{|c|}{ Cohort 2} \\
\hline & No. & $\%$ & No. & $\%$ \\
\hline Total & \multicolumn{2}{|c|}{245} & \multicolumn{2}{|c|}{185} \\
\hline \multicolumn{5}{|l|}{ Age } \\
\hline$\leq 45$ & 95 & 38.8 & 78 & 42.2 \\
\hline$>45$ & 150 & 61.2 & 107 & 57.8 \\
\hline \multicolumn{5}{|l|}{ Menopausal status } \\
\hline Premenopausal & 116 & 53.2 & & \\
\hline Postmenopausal & 102 & 46.8 & & \\
\hline Unknown & 27 & & & \\
\hline \multicolumn{5}{|l|}{ Clinical stage } \\
\hline । & 81 & 33.1 & 21 & 11.4 \\
\hline$\|$ & 91 & 37.1 & 80 & 43.2 \\
\hline III & 40 & 16.3 & 59 & 31.9 \\
\hline IV & 33 & 13.5 & 25 & 13.5 \\
\hline
\end{tabular}

T classification

$\begin{array}{ll}\mathrm{T}_{1} & 110 \\ \mathrm{~T}_{2} & 107 \\ \mathrm{~T}_{3} & 18 \\ \mathrm{~T}_{4} & 10\end{array}$

$N$ classification

$\mathrm{N}_{0}$
$\mathrm{~N}_{1}$
$\mathrm{~N}_{2}$
$\mathrm{~N}_{3}$

Distant metastasis

Yes

No

Estrogen receptor

Positive

Negative

Unknown

Progesterone receptor

Positive

Negative

Unkown

Her2

Positive
Negative
Unknown
MACC1 expression

High expression

Low expression
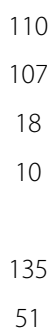

51
59.5

40.5

21.4

78.6

60.0

40.0

Table 1 Clinicopathologic characteristics of patient samples in Cohorts 1 and 2 (Continued)

\begin{tabular}{lcc}
\hline Endocrine therapy & & \\
tamoxifen & 122 & 43.8 \\
No treatment & 95 & 56.2 \\
Unknown & 28 & \\
\hline
\end{tabular}

used to calculate the effects of MACC1 expression on overall survival. The log-rank test showed that overall survival was significantly different between the low- and high-MACC1 expression groups $(P<0.001$, Figure $3 \mathrm{~A})$. Specifically, the cumulative 5-year survival rate was 91.44\% (95\% confidence interval, 0.841 to 0.954 ) in the low-MACC1 expression group $(\mathrm{n}=109)$, as opposed to the $72.78 \%$ survival rate $(95 \%$ confidence interval, 0.634 to 0.800$)$ in the high-MACC1 expression group ( $\mathrm{n}=$ 136). Furthermore, univariate and multivariate analyses were performed, and as shown in Table 4, a multivariate Cox regression analysis showed that after adjustment of tumor size, lymph node status and human hormone receptor status, MACC1 was an independent prognostic factor for overall survival in breast cancer. $(P=0.010$, Hazard ratio: $2.730,95 \%$ CI, 1.277 to 5.839 , Table 4). To confirm our finding in the cohort 1 , an independent second cohort of 185 patients from a different hospital, the Sun Yat-Sen University Cancer Center, was used for further analysis. Patients in cohort 2 were again classified into high- and low-MACC1 expression groups using an identical IHC method. We found that patients with high MACC1 expression had poorer overall survival than patients with low MACC1 expression $(P<0.001$, Figure $3 \mathrm{~B})$. Likewise, MACC1 was an independent prognostic factor for overall survival in breast cancer when a multivariate Cox regression analysis was used in cohort $2(P=0.001$, Hazard ratio: $3.190,95 \%$ CI, 1.651 to 6.163 , Table 5). Taken together, our results suggest that MACC1 might represent a novel and potentially useful independent biomarker for the prognosis of patients with breast cancer.

MACC1 overexpression identifies patients with poor clinical outcome within ER-positive or -negative subgroups of breast cancer

Because ER-positive and -negative breast cancers are considered to be two clinically as well as biologically different disease entities, we then separately investigated the prognostic value of MACC1 expression in these tumor subtypes. We stratified these patients into ERpositive and ER-negative groups according to the proportion of positive ER stain cells (cutoff: $\geq 10 \%$ ) and conducted Kaplan-Meier analysis survival analysis and long-rank test for each subgroup. Among the 154 breast cancer cases with positive ER status in cohort 1, high expression MACC1 was significantly associated with 
Table 2 Correlation between MACC1 expression and the clinicopathologic characteristics of the breast cancer patients

\begin{tabular}{|c|c|c|c|c|c|c|}
\hline \multirow[t]{3}{*}{ Characteristics } & \multirow{2}{*}{\multicolumn{3}{|c|}{$\frac{\text { Cohort } 1}{\text { MACC1 expression }}$}} & \multirow{2}{*}{\multicolumn{3}{|c|}{$\frac{\text { Cohort } 2}{\text { MACC1 expression }}$}} \\
\hline & & & & & & \\
\hline & Low & High & $P$-value & Low & High & $P$-value \\
\hline \multicolumn{7}{|l|}{ Age } \\
\hline$\leq 45$ & 44 & 51 & 0.647 & 29 & 49 & 0.504 \\
\hline$>45$ & 65 & 85 & & 45 & 62 & \\
\hline \multicolumn{7}{|l|}{ Menopausal status } \\
\hline Premenopausal & 56 & 60 & 0.799 & & & \\
\hline Postmenopausal & 51 & 51 & & & & \\
\hline \multicolumn{7}{|l|}{ Clinical stage } \\
\hline । & 43 & 38 & 0.001 & 19 & 2 & $<0.001$ \\
\hline$\|$ & 45 & 46 & & 37 & 43 & \\
\hline III & 15 & 25 & & 14 & 45 & \\
\hline IV & 5 & 28 & & 4 & 21 & \\
\hline \multicolumn{7}{|l|}{ T classification } \\
\hline $\mathrm{T}_{1}$ & 61 & 49 & 0.019 & 23 & 13 & $<0.001$ \\
\hline $\mathrm{T}_{2}$ & 39 & 68 & & 39 & 53 & \\
\hline$T_{3}$ & 6 & 12 & & 11 & 30 & \\
\hline $\mathrm{T}_{4}$ & 3 & 7 & & 1 & 15 & \\
\hline \multicolumn{7}{|l|}{ N classification } \\
\hline $\mathrm{N}_{0}$ & 67 & 68 & 0.050 & 44 & 26 & $<0.001$ \\
\hline$N_{1}$ & 25 & 26 & & 24 & 54 & \\
\hline $\mathrm{N}_{2}$ & 12 & 29 & & 4 & 26 & \\
\hline $\mathrm{N}_{3}$ & 5 & 13 & & 2 & 5 & \\
\hline \multicolumn{7}{|l|}{ Distant metastasis } \\
\hline Yes & 104 & 108 & $<0.001$ & 0 & 8 & 0.022 \\
\hline No & 5 & 28 & & 74 & 103 & \\
\hline \multicolumn{7}{|l|}{ Estrogen receptor } \\
\hline Positive & 79 & 95 & 0.653 & 36 & 65 & 0.185 \\
\hline Negative & 30 & 41 & & 38 & 46 & \\
\hline \multicolumn{7}{|c|}{ Progesterone receptor } \\
\hline Positive & 63 & 83 & 0.990 & 43 & 67 & 0.760 \\
\hline Negative & 32 & 42 & & 31 & 44 & \\
\hline \multicolumn{7}{|l|}{ Her2 } \\
\hline Positive & 21 & 22 & 0.862 & 8 & 13 & 0.480 \\
\hline Negative & 71 & 79 & & 36 & 41 & \\
\hline \multicolumn{7}{|l|}{ Endocrine therapy } \\
\hline tamoxifen & 62 & 60 & 0.614 & & & \\
\hline No treatment & 45 & 50 & & & & \\
\hline
\end{tabular}

relapse-free survival ( $P=0.003$, Figure $4 \mathrm{~A}$, left). For the overall survival, there was a significant difference between the MACC1 high- and low-expression groups (Figure 4A, right, $P=0.004$ ). We also conducted an overall survival analysis in 101 patients with ER-positive tumors in validation cohort 2 , and the association of high expression of MACC1 with poor prognosis was confirmed (Figure 4C, left, $P<0.001$ ).

Among ER-negative cases, the Kaplan-Meier analysis showed that MACC1 expression can predict survival in these patients. High MACC1 expression was significantly associated with decreased overall survival of these patients both in cohort 1 and cohort $2(P=0.017$ Figure $4 \mathrm{~B}$, right and $P<0.001$, Figure $4 \mathrm{C}$, right, respectively). For the relapse-free survival curves shown in ERbreast cancer patients, although the survival curve for MACC1 high-expression patients lied marginally below that for the MACC1 low-expression group, the difference was not statistically significant $(P=0.286)$. This may be due to the relatively small size of the study population $(\mathrm{n}=58)$, and apparently further investigation is needed for a definite conclusion.

Finally, to increase the power of the analysis, we pooled two prognostic datasets and examined whether the MACC1 was an independent prognostic factor for overall survival in ER+ as well as ER- breast cancer patients. The results showed that the prognostic value of MACC1 level in predicting poor survival in ER-positive and -negative breast cancers, respectively, remains significant in the multivariate analysis $(P<0.001$, Hazard ratio:3.747, $95 \% \mathrm{CI}, 1.799$ to 7.805 and $P=0.001$, Hazard ratio:3.076, $95 \% \mathrm{CI}, 1.560$ to 6.064 , Table 6 ).

\section{Discussion}

The current study represents the first demonstration of an association between MACC1 expression and breast cancer survival and the value of MACC1 as a prognostic marker for the disease. We find that high MACC1 expression is significantly related to reduced RFS and overall survival of breast cancer patients. As indicated by multivariate Cox regression analysis, MACC1 expression level represents an independent prognostic factor for overall survival. Furthermore, overexpression of MACC1 could identify poorer overall survival within both ER-positive and ERnegative breast cancer patient subgroups.

Metastasis remains the most important cause of deaths in breast cancer, and thus, understanding the clinical significance of metastasis-related molecules is key to developing novel and effective management strategies for breast cancer patients. While in other cancer types, such as colon cancer, gastric cancer and HCC, MACC1 has been found in fair numbers of patients $(n=41 \sim 60)$ to be pro-metastatic and predictive of disease prognosis $[2,3,6]$, the clinical significance of MACC1 in breast cancer was not previously studied, and whether it is of prognostic value in breast cancer, particularly for different patient subgroups, required enrollment of sufficient number of clinical cases to reach clinically relevant and meaningful conclusion. In our current study, two large 

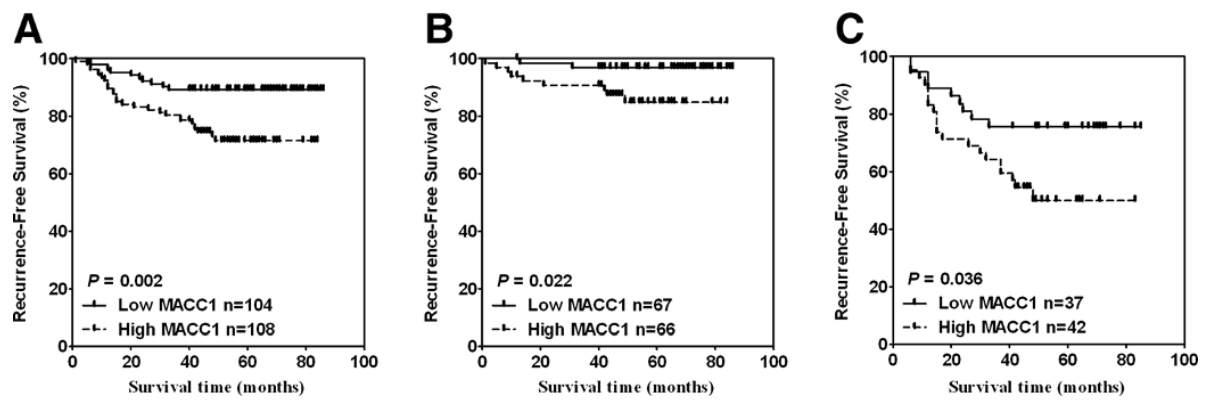

Figure 2 MACC1 expression in breast tumors is associated with reduced recurrence-free survival. A. Kaplan-Meier analysis of the probability of cumulative recurrence-free survival in breast cancer cases. B and $\mathbf{C}$. recurrence-free survival analysis of MACC1 in high- and lowexpression groups in $\mathrm{LN}-(\mathbf{B})$ and $\mathrm{LN}+(\mathbf{C})$ subgroups.

independent patient cohorts were employed, with which not only was overexpression of MACC1 in breast cancer identified and validated, but also its correlations with clinical staging, distant metastasis and patient survival were established. It is of particular note that for our cohort 1, in which RFS information was available for the enrolled patients, the study clearly demonstrated that when compared to the MACC1 low-expression group, MACC1 high-expression group showed a 2.5-fold increase of relapse rate. Interestingly, while the expression level of MACC1 correlates with the $\mathrm{N}$ classification in breast cancer, it is also of prognostic value in both $\mathrm{LN}$-positive and -

Table 3 Univariate and multivariate analyses of various prognostic variables for recurrence-free survival in cohort 1

\begin{tabular}{|c|c|c|c|c|}
\hline & \multicolumn{2}{|c|}{ Univariate analysis } & \multicolumn{2}{|c|}{ Multivariate analysis } \\
\hline & $P$-value & Hazard ratio $(95 \% \mathrm{Cl})$ & $P$-value & Hazard ratio $(95 \% \mathrm{Cl})$ \\
\hline \multicolumn{5}{|l|}{ Age } \\
\hline$\leq 45$ & 0.202 & $0.719(0.433-1.193)$ & & \\
\hline \multicolumn{5}{|l|}{$>45$} \\
\hline Menopausal status & 0.768 & $0.915(0.508-1.648)$ & & \\
\hline \multicolumn{5}{|l|}{ Premenopausal } \\
\hline \multicolumn{5}{|l|}{ Postmenopausal } \\
\hline \multicolumn{5}{|l|}{ Tumor size (cm) } \\
\hline$\leq 2$ & 0.000 & $3.479(1.881-6.435)$ & 0.146 & $1.649(0.840-3.237)$ \\
\hline \multicolumn{5}{|l|}{$>2$} \\
\hline \multicolumn{5}{|l|}{ Lymph node status } \\
\hline Negative & $<0.001$ & $5.424(2.932-10.036)$ & $<0.001$ & $4.205(2.205-8.017)$ \\
\hline \multicolumn{5}{|l|}{ Positive } \\
\hline \multicolumn{5}{|l|}{ ER } \\
\hline Positive & 0.012 & $0.519(0.310-0.866)$ & 0.060 & $0.606(0.359-1.021)$ \\
\hline \multicolumn{5}{|l|}{ Negative } \\
\hline \multicolumn{5}{|l|}{ PR } \\
\hline Positive & 0.020 & $0.528(0.308-0.906)$ & & \\
\hline \multicolumn{5}{|l|}{ Negative } \\
\hline \multicolumn{5}{|l|}{ ErbB-2 } \\
\hline Positive & 0.220 & $1.527(0.777-3.004)$ & & \\
\hline \multicolumn{5}{|l|}{ Negative } \\
\hline \multicolumn{5}{|l|}{ MACC1 expression } \\
\hline Positive & 0.000 & $3.021(1.659-5.501)$ & 0.006 & $2.378(1.279-4.424)$ \\
\hline Negative & & & & \\
\hline
\end{tabular}



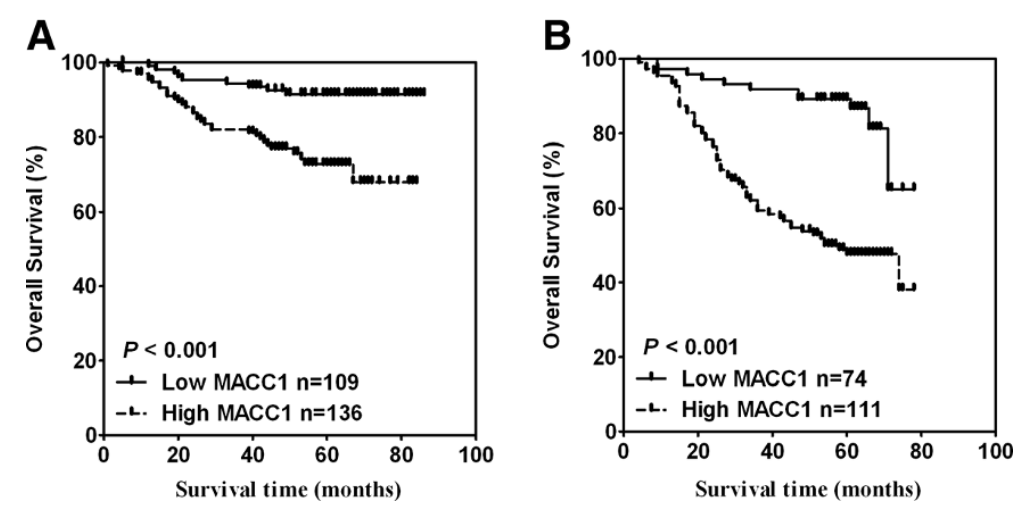

Figure 3 MACC1 expression and overall survival analysis. A. Kaplan-Meier curves with univariate analysis (log-rank) for patients with low- versus high-MACC1 expression tumors in cohort 1. B. Overall survival analysis and comparison in patients with high- and low-MACC1 groups in cohort 2.

negative patients. Importantly, since multivariate analyses suggest that either expression level of MACC1 or lymph node status is an independent prognostic parameter for RFS, quantification of MACC1 expression may represent a useful approach, in addition to lymph node status, to evaluating the risk of recurrence, aside from its identified value for predicting overall survival of breast cancer patients by this study.

The differential clinical manifestations between ERpositive and -negative breast cancers have been

Table 4 Univariate and multivariate analyses of various prognostic variables for overall survival in cohort 1

\begin{tabular}{|c|c|c|c|c|}
\hline & \multicolumn{2}{|c|}{ Univariate analysis } & \multicolumn{2}{|c|}{ Multivariate } \\
\hline & $P$ & Hazard ratio $(95 \% \mathrm{Cl})$ & $P$ & Hazard ratio $(95 \% \mathrm{Cl})$ \\
\hline \multicolumn{5}{|l|}{ Age } \\
\hline$\leq 45$ & 0.261 & 0.709 (0.389-1.291) & & \\
\hline \multicolumn{5}{|l|}{$>45$} \\
\hline Menopausal status & 0.589 & $1.223(0.590-2.534)$ & & \\
\hline \multicolumn{5}{|l|}{ Premenopausal } \\
\hline \multicolumn{5}{|l|}{ Postmenopausal } \\
\hline \multicolumn{5}{|l|}{ Tumor size $(\mathrm{cm})$} \\
\hline$\leq 2$ & $<0.001$ & $5.930(2.501-14.064)$ & 0.027 & $2.833(1.125-7.132)$ \\
\hline \multicolumn{5}{|l|}{$>2$} \\
\hline \multicolumn{5}{|l|}{ Lymph node status } \\
\hline Negative & $<0.001$ & $5.581(2.674-11.648)$ & 0.001 & $3.836(1.786-8.239)$ \\
\hline \multicolumn{5}{|l|}{ Positive } \\
\hline \multicolumn{5}{|l|}{ ER } \\
\hline Positive & 0.11 & $0.458(0.251-0.836)$ & 0.044 & $0.534(0.290-0.983)$ \\
\hline \multicolumn{5}{|l|}{ Negative } \\
\hline \multicolumn{5}{|l|}{ PR } \\
\hline Positive & 0.076 & $0.557(0.292-1.064)$ & & \\
\hline \multicolumn{5}{|l|}{ Negative } \\
\hline \multicolumn{5}{|l|}{ ErbB-2 } \\
\hline Positive & 0.837 & $1.101(0.440-2.758)$ & & \\
\hline \multicolumn{5}{|l|}{ Negative } \\
\hline \multicolumn{5}{|l|}{ MACC1 expression } \\
\hline Positive & 0.001 & $3.682(1.756-7.721)$ & 0.010 & $2.730(1.277-5.839)$ \\
\hline Negative & & & & \\
\hline
\end{tabular}


Table 5 Univariate and multivariate analyses of various prognostic variables for overall survival in cohort 2

\begin{tabular}{|c|c|c|c|c|}
\hline & \multicolumn{2}{|c|}{ Univariate analysis } & \multicolumn{2}{|c|}{ Multivariate } \\
\hline & $P$ & Hazard ratio $(95 \% \mathrm{Cl})$ & $P$ & Hazard ratio $(95 \% \mathrm{Cl})$ \\
\hline \multicolumn{5}{|l|}{ Age } \\
\hline$\leq 45$ & 0.808 & $1.061(0.657-1.713)$ & & \\
\hline \multicolumn{5}{|l|}{$>45$} \\
\hline \multicolumn{5}{|c|}{ Tumor size (cm) } \\
\hline$\leq 2$ & $<0.001$ & 3.449 (2.131-5.584) & $<0.001$ & $2.834(1.741-4.612)$ \\
\hline \multicolumn{5}{|l|}{$>2$} \\
\hline \multicolumn{5}{|c|}{ Lymph node status } \\
\hline Negative & $<0.001$ & 3.657 (1.960-6.823) & 0.001 & $2.936(1.540-5.597)$ \\
\hline \multicolumn{5}{|l|}{ Positive } \\
\hline \multicolumn{5}{|l|}{ ER } \\
\hline Positive & 0.793 & $0.938(0.583-1.509)$ & & \\
\hline \multicolumn{5}{|l|}{ Negative } \\
\hline \multicolumn{5}{|l|}{ PR } \\
\hline Positive & 0.036 & $0.603(0.375-0.968)$ & 0.002 & $0.465(0.286-0.757)$ \\
\hline \multicolumn{5}{|l|}{ Negative } \\
\hline \multicolumn{5}{|l|}{ ErbB-2 } \\
\hline Positive & 0.886 & $0.937(0.383-2.292)$ & & \\
\hline \multicolumn{5}{|l|}{ Negative } \\
\hline \multicolumn{5}{|c|}{ MACC1 expression } \\
\hline Positive & $<0.001$ & $4.564(2.392-8.709)$ & 0.001 & $3.190(1.651-6.163)$ \\
\hline Negative & & & & \\
\hline
\end{tabular}

recognized for many years [28], and more recently, they are considered to be two different molecular types of the disease characterized by distinct gene expression patterns [29]. Prognostic significance of biomarkers has been found to be inconsistent between ER-positive and negative breast cancer [30,31]. In previous reports studying the prognosis of the two breast cancer groups, results obtained have been contradictory, possibly reflecting the molecular heterogeneity of breast cancers [32]. In this study, survival analysis was conducted and found to be prognostic in both ER-positive and ERnegative groups in two independent cohorts, it would be of great interest to further explore whether MACC1 plays an important role in promoting tumor progression through mechanisms common in different types of breast cancer. It is well recognized that breast cancer patients with positive ER, which account for at least twothirds of all breast cancer cases, display better clinical outcomes than those with negative ER. ER-positive breast cancer patients usually benefit from adjuvant endocrine therapy, such as tamoxifen and its analogues [33]. Furthermore, it has been reported that in ERpositive patients, postoperative tamoxifen treatment could highly effectively reduce the chance of recurrence without addition of chemotherapy [34]. However, in the current clinical practice, postoperative chemotherapy is prescribed quite often in many areas of the world, which might subject patients to overtreatment and the accompanying adverse effects. Therefore, it would be clinically important to identify individuals with low-risk of recurrence in ER-positive patients so that unnecessary treatment can be avoided for a significant fraction of breast cancer patients. On the other hand, it is equally important to distinguish favorable prognosis factors for patients bearing ER-negative tumors with good prognosis who may not need further treatment after complete resection. The finding that MACC1 expression has prognostic values in both ER-positive and -negative breast cancer subgroups warrants further evaluation to explore whether the biomarker can be clinically useful in the decision-making process for the treatment of breast cancer patients.

The molecular pathways underlying a possible biological role of MACC1 in breast cancer progression are yet to be elucidated. Previous studies have shown that MACC1 acts as a transcription activator for c-MET and as a key regulator of HGF-c-MET signaling pathway in colon cancer, promoting proliferation, invasion and HGF-induced scattering of colon cancer cells and xenograft growth and metastasis in vivo [1]. Moreover, it has been recognized that the $c$ - 

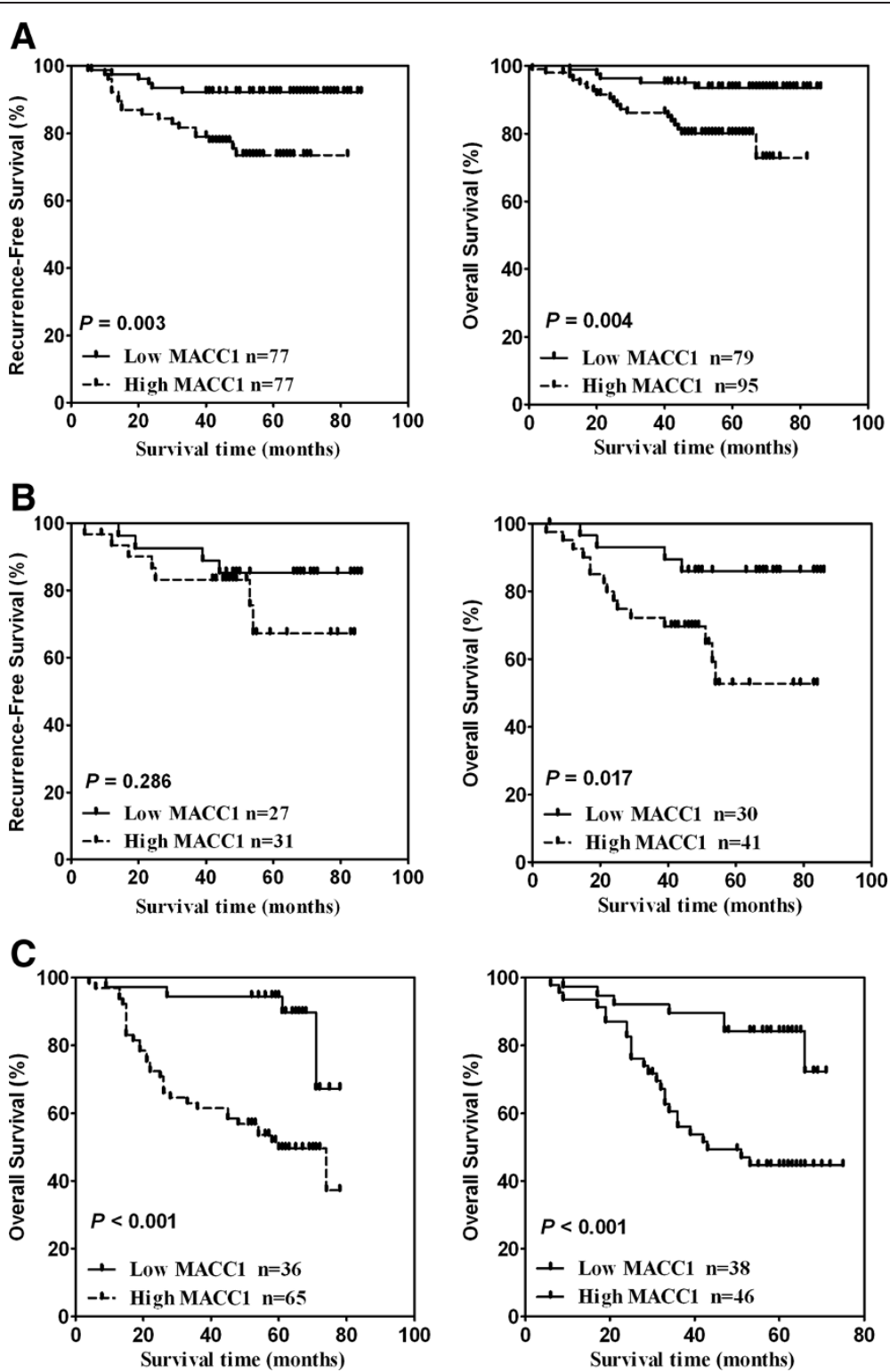

Figure 4 Kaplan-Meier estimates of relapse-free survival and overall survival according to MACC1 expression level in subgroups of ER- and ER+ patients in two independent datasets. A. Relapse-free survival and overall survival of ER+ breast cancer patients in cohort 1. B. Relapse-free survival and overall survival of ER- breast cancer patients in cohort 1. C. Overall survival of ER+ and ER- breast patients in cohort 2.

MET oncogene, which codes for the tyrosine kinase receptor for HGF, enhances invasion and metastasis of various types of cancer cells, including breast cancer, through stimulating proliferation, survival, invasiveness and angiogenesis [35-37]. Furthermore, c-MET overexpression in breast tumors has been found to be associated with disease progression and correlate with poor survival [23,37-41]. Hence, our finding that MACC1 overexpression is closely related to the clinical outcome of breast cancer warrants further and in-depth investigation on whether and how MACC1 interacts with the HGF-c-MET pathway, or other signaling pathways, in this highly prevalent malignancy.

\section{Conclusions}

In conclusion, this is the first study aimed at evaluating the possibility of using MACC1 as a clinically relevant indicator for breast cancer recurrence and as a prognostic marker for patient survival in breast cancer. In addition, MACC1 expression status may be useful for evaluating the effectiveness of novel anti-breast cancer therapeutic strategies and for developing rational criteria for the selection of treatments. Toward this end, further investigation on the mechanism by which MACC1 is involved in the development and progression of breast cancer and prospective studies on the prognostic significance of MACC1 are needed. 
Table 6 Multivariate analysis of various prognostic variables for overall survival in ER+ and ER- breast cancer subtypes

\begin{tabular}{|c|c|c|c|c|}
\hline & \multicolumn{2}{|c|}{ ER+ } & \multicolumn{2}{|c|}{ ER- } \\
\hline & $P$ & Hazard ratio $(95 \% \mathrm{Cl})$ & $P$ & Hazard ratio $(95 \% \mathrm{Cl})$ \\
\hline \multicolumn{5}{|c|}{ Tumor size (cm) } \\
\hline$\leq 2$ & 0.004 & $2.240(1.289-3.892)$ & 0.070 & $1.696(0.958-3.000)$ \\
\hline \multicolumn{5}{|l|}{$>2$} \\
\hline \multicolumn{5}{|c|}{ Lymph node status } \\
\hline Negative & $<0.001$ & 3.679 (1.824-7.422) & $<0.001$ & $3.671(1.878-7.173)$ \\
\hline \multicolumn{5}{|l|}{ Positive } \\
\hline \multicolumn{5}{|c|}{ MACC1 expression } \\
\hline Positive & $<0.001$ & 3.747 (1.799-7.805) & 0.001 & $3.076(1.560-6.064)$ \\
\hline Negative & & & & \\
\hline
\end{tabular}

\section{Methods}

\section{Patient information and tissue specimens}

This study was conducted on a total of 430 paraffinembedded breast cancer samples, which were histopathologically and clinically diagnosed at the First Affiliated Hospital of Sun Yat-sen University and the Sun Yat-sen University Cancer Center from 2000 to 2002. In the first cohort, a total of 245 primary breast cancer patients were treated at First Affiliated Hospital of Sun Yat-sen University. Clinical information, including age, tumor size, lymph node status, clinical stage, ER status, PR status, HER2 expression and clinical followup data, was obtained from all patients' medical records (when available). For each patient, recurrence-free survival (RFS) was defined as the time interval between the date of diagnosis to first recurrence (including local or regional recurrence and organs metastasis). Overall survival (OS) was defined as the time from date of diagnosis to death whereby breast cancer was the primary or underlying cause of death. Patients who were alive at the last follow-up were censored at the follow-up dates, and patients who died from causes other than breast cancer were censored at the time of death. For the use of these clinical materials for research purposes, prior patients' consents and approval from the Sun Yat-sen University and First Affiliated Hospital Institutional Board were obtained. All samples were collected and analyzed with prior written informed consent from the patients.

To further verify the results from the first cohort, an independent second cohort of patients was included in this study, which enrolled 185 patients treated at the Sun YatSen University Cancer Center. In the second cohort, only OS information is available as the follow-up data. Clinical and clinicopathologic classification and staging were determined according to the American Joint Committee on Cancer guideline [42]. Clinical information of the patients and samples is summarized in Table 1. For the use of clinical materials for research purposes, prior patients' consents and approval were obtained from the Sun YatSen University and Cancer Center Institutional Board. All samples were collected and analyzed with prior written informed consent from the patients. Four normal breast tissues were obtained from the reduction mammoplasty material at the Department of Plastic Surgery, the First Affiliated Hospital of Sun Yat-Sen University and approved by the Sun Yat-Sen University and First Affiliated Hospital Institutional Board. Samples were collected and analyzed with written informed consent.

Eight pared tumors and corresponding normal breast tissues were collected at surgically resected tissues at the Sun Yat-Sen University Cancer Center and stored immediately at $-80^{\circ} \mathrm{C}$ until analysis. All specimens were confirmed by routine histopathologic analysis. Written informed consent was obtained from all patients.

\section{Western blotting}

Western blotting analysis was performed as described [43]. Fresh tissue was grounded to powder in liquid nitrogen and then lysed with sampling buffer [62.5 $\mathrm{mmol} / \mathrm{L}$ Tris- $\mathrm{HCl}$ (pH 6.8), 10\% glycerol, and 2\% SDS] and boiled for $5 \mathrm{~min}$. Protein concentration was determined using the Bradford assay (Bio-Rad Laboratories, Hercules, CA). Equal amounts of protein was separated electrophoretically on $7.5 \%$ SDS-polyacrylamide gels and transferred onto polyvinylidene difluoride membranes (Roche Diagnostics, Mannheim, Germany). The membrane was probed with an anti-MACC1 rabbit antibody (1:1,000 dilution; ProSci Inc. Poway, CA). Expression of MACC1 was determined using horseradish peroxidase-conjugated anti-rabbit immunoglobulin G diluted at 1:3000 and enhanced chemiluminescence method (Pierce, Rockford, IL) according to the manufacturer's suggested protocol. The membrane was stripped and re-probed with an anti- $\alpha$-tubulin mouse monoclonal antibody (1:1,000 dilution; Sigma-Aldrich, St Louis, MO) as a loading control. 


\section{Immunohistochemistry analysis (IHC)}

IHC was performed to investigate altered protein expression in 430 human breast cancer tissues and 4 normal breast tissues. Rabbit anti-MACC1 (1:500; ProSci Inc. Poway, CA) and a MACC1 peptide (ProSci Inc. Poway, CA) was used in this study. The IHC procedure was carried out as previously reported [44].

The degree of immunostaining of formalin-fixed, paraffin-embedded sections was reviewed and scored independently by two observers, who were blinded to clinical data, based on both the proportion of positively stained tumor cells and the intensity of staining [45-47]. The proportion of tumor cells was scored as follows: 0 (no positive tumor cells), 1 ( $<10 \%$ positive tumor cells), $2(10-50 \%$ positive tumor cells), and 3 ( $>50 \%$ positive tumor cells). The intensity of staining was graded according to the following criteria: 0 (no staining); 1 (weak staining = light yellow), 2 (moderate staining = yellow brown), and 3 (strong staining = brown). The staining index was calculated by multiplying the staining intensity score and the proportion of positive tumor cells. Using this method of assessment, we evaluated the expression of MACC1 in benign breast epithelium and malignant lesions by determining the staining index, resulting in scores as $0,1,2,3,4,6$ or 9 . Cutoff values for MACC1 were chosen on the basis of a measurement of heterogeneity with the log-rank test statistical analysis with respect to overall survival. An optimal cutoff value was identified: the staining index score of $\geq 6$ defined tumors as high MACC1 expression and $\leq 4$ as low expression of MACC1. This IHC analysis has been used in previous publications as a widely accepted method [44,48-53].

\section{Statistical analysis}

All statistical analyses were carried out using the SPSS 10.0 statistical software package (SPSS Inc, Chicago, IL). Pearson's chi-square test was used to analyze the correlation between MACC1 expression and the clinicopathologic characteristics. Survival curves were plotted using the Kaplan-Meier method and compared with the logrank test. The significance of various variables for survival was analyzed by the Cox proportional hazards model in the multivariate analysis. $P<0.05$ in all cases was considered statistically significant.

\section{Abbreviations}

ER: Estrogen receptor; HCC: Hepatocellular carcinoma;

IHC: Immunohistochemistry; LN: Lymph nodes; MACC1: Metastasis-associated in colon cancer-1; OS: Overall survival; PR: Progesterone receptor;

TNM: Tumor-node-metastasis; RFS: Reduced recurrence-free survival.

\section{Competing interests}

The authors declare that they have no competing interests.

\section{Authors' contributions}

$Y H, H Z$, JC and LF carried out the IHC analysis and statistical analysis. HZ, CY, JW and $X Z$ contributed clinical information. $Y H, H Z$ and $M L$ participated in the interpretation of data and the critical review of the manuscript. YH wrote the article and $M L$ revised it. ML provided the general ideas of this manuscript and co-designed and coordinated the study. All authors read and approved the final manuscript.

\section{Acknowledgments and Funding}

This work was supported by: National Science and Technique Major Project (201005022-2, 2012ZX09102101-017, 2012ZX10004213, 311030); and The Key Science and Technique Research Project of Guangdong Province (2010B030600003, 2009010058).

\section{Author details}

${ }^{1}$ Department of Microbiology, Zhongshan School of Medicine, Sun Yat-Sen University, Guangzhou, Guangdong 510080, China. ${ }^{2}$ Key Laboratory of Tropical Disease Control (Sun Yat-Sen University), Ministry of Education, Guangzhou, Guangdong 510080, China. ${ }^{3}$ Department of Pathology, Sun Yatsen University Cancer Center, Sun Yat-Sen University, Guangzhou, Guangdong, China. ${ }^{4}$ Department of Breast Disease Center, The First Affiliated Hospital, Sun Yat-Sen University, Guangzhou 510080, China.

Received: 16 December 2012 Accepted: 4 February 2013

Published: 18 March 2013

\section{References}

1. Stein U, Walther W, Arlt F, Schwabe H, Smith J, Fichtner I, Birchmeier W, Schlag PM: MACC1, a newly identified key regulator of HGF-MET signaling, predicts colon cancer metastasis. Nat Med 2009, 15:59-67.

2. Shirahata A, Shinmura K, Kitamura Y, Sakuraba K, Yokomizo K, Goto T, Mizukami H, Saito M, Ishibashi K, Kigawa G, et al: MACC1 as a marker for advanced colorectal carcinoma. Anticancer Res 2010, 30:2689-2692.

3. Shirahata A, Sakata M, Kitamura Y, Sakuraba K, Yokomizo K, Goto T, Mizukami H, Saito M, Ishibashi K, Kigawa G, et al: MACC 1 as a marker for peritoneal-disseminated gastric carcinoma. Anticancer Res 2010, 30:3441-3444

4. Chundong $G$, Uramoto $H$, Onitsuka $T$, Shimokawa $H$, Iwanami T, Nakagawa M, Oyama T, Tanaka F: Molecular diagnosis of MACC1 status in lung adenocarcinoma by immunohistochemical analysis. Anticancer Res 2011, 31:1141-1145

5. Shimokawa $H$, Uramoto $H$, Onitsuka T, Chundong G, Hanagiri T, Oyama T, Yasumoto K: Overexpression of MACC1 mRNA in lung adenocarcinoma is associated with postoperative recurrence. J Thorac Cardiovasc Surg 2011, 141:895-898.

6. Shirahata A, Fan W, Sakuraba K, Yokomizo K, Goto T, Mizukami H, Saito M, Ishibashi K, Kigawa G, Nemoto H, et al: MACC 1 as a marker for vascular invasive hepatocellular carcinoma. Anticancer Res 2011, 31:777-780.

7. World Cancer Report: International Agency for Research on Cancer (IARC). 2008.

8. Parkin DM, Bray F, Ferlay J, Pisani P: Global cancer statistics, 2002. CA Cancer J Clin 2005, 55:74-108.

9. Shulman LN, Willett W, Sievers A, Knaul FM: Breast cancer in developing countries: opportunities for improved survival. J Oncol 2010, 2010:595167.

10. Ali SM, Harvey HA, Lipton A: Metastatic breast cancer: overview of treatment. Clin Orthop Relat Res 2003, 415(Suppl):S132-S137.

11. Miller KD, Sledge GW Jr: The role of chemotherapy for metastatic breast cancer. Hematol Oncol Clin North Am 1999, 13:415-434.

12. Wingo PA, Tong T, Bolden S: Cancer statistics, 1995. CA Cancer J Clin 1995, 45:8-30.

13. Karrison TG, Ferguson DJ, Meier P: Dormancy of mammary carcinoma after mastectomy. J Natl Cancer Inst 1999, 91:80-85.

14. Bentzon N, During M, Rasmussen BB, Mouridsen $H$, Kroman N: Prognostic effect of estrogen receptor status across age in primary breast cancer. Int J Cancer 2008, 122:1089-1094.

15. Dunnwald LK, Rossing MA, Li Cl: Hormone receptor status, tumor characteristics, and prognosis: a prospective cohort of breast cancer patients. 2007/01/24th edition; 2007

16. Rosen PP, Cranor ML: Secretory carcinoma of the breast. Arch Pathol Lab Med 1991, 115:141-144. 
17. Trendell-Smith NJ, Peston D, Shousha S: Adenoid cystic carcinoma of the breast: a tumour commonly devoid of oestrogen receptors and related proteins. Histopathology 1999, 35:241-248

18. Slamon DJ, Clark GM, Wong SG, Levin WJ, Ullrich A, McGuire WL: Human breast cancer: correlation of relapse and survival with amplification of the HER-2/neu oncogene. Science 1987, 235:177-182.

19. Slamon DJ, Godolphin W, Jones LA, Holt JA, Wong SG, Keith DE, Levin WJ, Stuart SG, Udove J, Ullrich A, et al: Studies of the HER-2/neu proto-oncogene in human breast and ovarian cancer. Science 1989, 244:707-712.

20. Ravdin PM, Chamness GC: The c-erbB-2 proto-oncogene as a prognostic and predictive marker in breast cancer: a paradigm for the development of other macromolecular markers-a review. Gene 1995, 159:19-27.

21. Buzdar AU, Ibrahim NK, Francis D, Booser DJ, Thomas ES, Theriault RL, Pusztai L, Green MC, Arun BK, Giordano SH, et al: Significantly higher pathologic complete remission rate after neoadjuvant therapy with trastuzumab, paclitaxel, and epirubicin chemotherapy: results of a randomized trial in human epidermal growth factor receptor 2-positive operable breast cancer. J Clin Oncol 2005, 23:3676-3685

22. Vogel CL, Cobleigh MA, Tripathy D, Gutheil JC, Harris LN, Fehrenbacher L, Slamon DJ, Murphy M, Novotny WF, Burchmore M, et al: Efficacy and safety of trastuzumab as a single agent in first-line treatment of HER2overexpressing metastatic breast cancer. J Clin Oncol 2002, 20:719-726.

23. Ponzo MG, Lesurf $R$, Petkiewicz S, O'Malley FP, Pinnaduwage D, Andrulis IL, Bull SB, Chughtai N, Zuo D, Souleimanova M, et al: Met induces mammary tumors with diverse histologies and is associated with poor outcome and human basal breast cancer. Proc Natl Acad Sci U S A 2009, 106:12903-12908.

24. Raghav KP, Wang W, Liu S, Chavez-MacGregor M, Meng X, Hortobagyi GN, Mills GB, Meric-Bernstam F, Blumenschein GR Jr, Gonzalez-Angulo AM: cMET and phospho-cMET protein levels in breast cancers and survival outcomes. Clin Cancer Res 2012, 18:2269-2277.

25. Lengyel E, Prechtel D, Resau JH, Gauger K, Welk A, Lindemann K, Salanti G, Richter T, Knudsen B, Harbeck N, Vande Woude GF: C-Met overexpression in node-positive breast cancer identifies patients with poor clinical outcome independent of Her2/neu. Int J Cancer 2005, 113:678-682.

26. Liu X, Newton RC, Scherle PA: Developing c-MET pathway inhibitors for cancer therapy: progress and challenges. Trends Mol Med 2010, 16:37-45.

27. Valagussa $P$, Bonadonna $G$, Veronesi U: Patterns of relapse and survival following radical mastectomy. Analysis of 716 consecutive patients. Cancer 1978, 41:1170-1178.

28. Hess KR, Pusztai L, Buzdar AU, Hortobagyi GN: Estrogen receptors and distinct patterns of breast cancer relapse. Breast Cancer Res Treat 2003, 78:105-118.

29. Gruvberger S, Ringner M, Chen Y, Panavally S, Saal LH, Borg A, Ferno M, Peterson C, Meltzer PS: Estrogen receptor status in breast cancer is associated with remarkably distinct gene expression patterns. Cancer Res 2001, 61:5979-5984.

30. Pan D, Kocherginsky M, Conzen SD: Activation of the glucocorticoid receptor is associated with poor prognosis in estrogen receptor-negative breast cancer. Cancer Res 2011, 71:6360-6370.

31. Klintman M, Bendahl PO, Grabau D, Lovgren K, Malmstrom P, Ferno M: The prognostic value of Ki67 is dependent on estrogen receptor status and histological grade in premenopausal patients with node-negative breast cancer. Mod Pathol 2010, 23:251-259.

32. Iwamoto T, Bianchini G, Booser D, Qi Y, Coutant C, Shiang CY, Santarpia L, Matsuoka J, Hortobagyi GN, Symmans WF, et al: Gene pathways associated with prognosis and chemotherapy sensitivity in molecular subtypes of breast cancer. J Natl Cancer Inst 2011, 103:264-272.

33. Tamoxifen for early breast cancer: an overview of the randomised trials: Early Breast Cancer Trialists' Collaborative Group. Lancet 1998, 351:1451-1467.

34. Paik S, Shak S, Tang G, Kim C, Baker J, Cronin M, Baehner FL, Walker MG Watson D, Park T, et al: A multigene assay to predict recurrence of tamoxifen-treated, node-negative breast cancer. N Engl J Med 2004, 351:2817-2826.

35. Birchmeier C, Birchmeier W, Gherardi E, Vande Woude GF: Met, metastasis, motility and more. Nat Rev Mol Cell Biol 2003, 4:915-925.

36. Yao $Y$, Jin L, Fuchs A, Joseph A, Hastings HM, Goldberg ID, Rosen EM: Scatter factor protein levels in human breast cancers: clinicopathological and biological correlations. Am J Pathol 1996, 149:1707-1717.

37. Ghoussoub RA, Dillon DA, D'Aquila T, Rimm EB, Fearon ER, Rimm DL: Expression of c-met is a strong independent prognostic factor in breast carcinoma. Cancer 1998, 82:1513-1520.
38. Beviglia L, Matsumoto K, Lin CS, Ziober BL, Kramer RH: Expression of the c-Met/HGF receptor in human breast carcinoma: correlation with tumor progression. Int J Cancer 1997, 74:301-309.

39. Welm AL, Kim S, Welm BE, Bishop JM: MET and MYC cooperate in mammary tumorigenesis. Proc Natl Acad Sci U S A 2005, 102:4324-4329.

40. Garcia S, Dales JP, Charafe-Jauffret E, Carpentier-Meunier S, Andrac-Meyer L, Jacquemier J, Andonian C, Lavaut MN, Allasia C, Bonnier P, Charpin C: Poor prognosis in breast carcinomas correlates with increased expression of targetable CD146 and c-Met and with proteomic basal-like phenotype. Hum Pathol 2007, 38:830-841.

41. Tolgay Ocal I, Dolled-Filhart M, D'Aquila TG, Camp RL, Rimm DL: Tissue microarray-based studies of patients with lymph node negative breast carcinoma show that met expression is associated with worse outcome but is not correlated with epidermal growth factor family receptors. Cancer 2003, 97:1841-1848.

42. Greene FL PDL, Fleming ID: Breast cancer in AJCC cancer staging handbook. TNM classification of malignant tumors. 6th edition. New York: Springer Verlag; 2002:255-281.

43. Li J, Guan HY, Gong LY, Song LB, Zhang N, Wu J, Yuan J, Zheng YJ, Huang ZS, Li M: Clinical significance of sphingosine kinase-1 expression in human astrocytomas progression and overall patient survival. Clin Cancer Res 2008, 14:6996-7003.

44. Li J, Zhang N, Song LB, Liao WT, Jiang LL, Gong LY, Wu J, Yuan J, Zhang HZ, Zeng MS, Li M: Astrocyte elevated gene-1 is a novel prognostic marker for breast cancer progression and overall patient survival. Clin Cancer Res 2008, 14:3319-3326.

45. Song LB, Liao WT, Mai HQ, Zhang HZ, Zhang L, Li MZ, Hou JH, Fu LW, Huang WL, Zeng $Y X$, Zeng MS: The clinical significance of twist expression in nasopharyngeal carcinoma. Cancer Lett 2006, 242:258-265.

46. Geisler SA, Olshan AF, Weissler MC, Cai J, Funkhouser WK, Smith J, Vick K: p16 and p53 Protein expression as prognostic indicators of survival and disease recurrence from head and neck cancer. Clin Cancer Res 2002, 8:3445-3453.

47. Fukuoka J, Fujii T, Shih JH, Dracheva T, Meerzaman D, Player A, Hong K, Settnek S, Gupta A, Buetow K, et al: Chromatin remodeling factors and BRM/BRG1 expression as prognostic indicators in non-small cell lung cancer. Clin Cancer Res 2004, 10:4314-4324.

48. Wang $Q$, Zheng $X L$, Yang L, Shi F, Gao LB, Zhong YJ, Sun H, He F, Lin Y, Wang $X$ : Reactive oxygen species-mediated apoptosis contributes to chemosensitization effect of saikosaponins on cisplatin-induced cytotoxicity in cancer cells. J Exp Clin Cancer Res 2010, 29:159.

49. Collett K, Eide GE, Arnes J, Stefansson IM, Eide J, Braaten A, Aas T, Otte AP, Akslen LA: Expression of enhancer of zeste homologue 2 is significantly associated with increased tumor cell proliferation and is a marker of aggressive breast cancer. Clin Cancer Res 2006, 12:1168-1174.

50. Salvesen HB, MacDonald N, Ryan A, Iversen OE, Jacobs IJ, Akslen LA, Das S: Methylation of hMLH1 in a population-based series of endometrial carcinomas. Clin Cancer Res 2000, 6:3607-3613.

51. Salvesen HB, Das $S$, Akslen LA: Loss of nuclear p16 protein expression is not associated with promoter methylation but defines a subgroup of aggressive endometrial carcinomas with poor prognosis. Clin Cancer Res 2000, 6:153-159.

52. Salvesen $H B$, Iversen $O E$, Akslen $L A$ : Identification of high-risk patients by assessment of nuclear $\mathrm{Ki}-67$ expression in a prospective study of endometrial carcinomas. Clin Cancer Res 1998, 4:2779-2785.

53. Gravdal K, Halvorsen OJ, Haukaas SA, Akslen LA: A switch from E-cadherin to $\mathrm{N}$-cadherin expression indicates epithelial to mesenchymal transition and is of strong and independent importance for the progress of prostate cancer. Clin Cancer Res 2007, 13:7003-7011.

doi:10.1186/2045-3701-3-16

Cite this article as: Huang et al:: Overexpression of MACC1 and Its significance in human Breast Cancer Progression. Cell \& Bioscience 2013 3:16. 